\title{
Çocuk Ürolojisi'nde Lazer Kullanımı
}

\author{
Bilal Günaydın¹, Mesrur Selçuk Sılay²
}

Medeniyet Üniversitesi Göztepe Eğitim ve Araştırma Hastanesi, Üroloji Anabilim Dalı ${ }^{1}$, Çocuk Ürolojisi Bilim Dalı², İstanbul

\section{Giriș}

Son 20 yılda teknolojik gelişmelere paralel olarak endoskoPik aletlerin incelmesi, yeni endoskopik tekniklerin geliştirilmesi ve bu teknolojiler kullanılarak erişkin hastalardaki klinik tecrübelerin artması ile artık çocuk ürolojisinde de giderek artan sıklıkta minimal invazif cerrahiler (MIC) uygulanmaya başlanmıştır (1,2). MIC'deki bu artış çocuklarda güvenle kullanılabilen lazer enerji kaynaklarının kullanımını da artırmıştır. Endoskopide lazer kullanımı ile tedavinin etkinliği artmakta, kanama miktarı azalmaktadır (3).

Çocuk ürolojisinde Holmiyum: yttrium-aluminum-garnet (Ho: YAG) lazer en sık tercih edilen lazer türüdür. Ho: YAG lazer, 2140 nanometre dalga boyutunda, 350 mikro saniyelik atım süresine, atım başına 0.2 ile 2 jul enerji skalasına ve suda hızlı absorbe olabilme özeliğine sahip bir lazer türüdür. Yumuşak dokudaki termal etkinliği $0.4 \mathrm{~mm}$ olup, sualtı ortamda hızla absorbe olabildiğinden endoskopik cerrahide güvenle kullanılmaktadır $(3,4)$. Ho:YAG lazer üriner sistem taşlarının tedavisi dışında üreteropelvik bileşke, üreter ve üretra darlıklarının tedavisinde, posterior üretral valvlerin ablasyonunda, fibroepitelyal polip ve tümör eksizyonlarında ve üreterosel ponksiyonunda kullanılabilmektedir.

Bu bölümde güncel literatür eşliğinde çocuk ürolojisindeki hastalıklarda lazer kullanımına değinilmiştir.

\section{Pediatrik Taş Hastalarında Lazer Litotripsi}

Çocuklardaki taş prevelansı gelişmiş ülkelerde \%1-8 iken, gelişmekte olan ülkelerde bu oran \%5-15'dir (5). Ülkemizin de içinde bulunduğu endemik ülkelerde pediatrik taş hastalarının tedavisinde perkütan ve üreteroskopik ameliyatların oranı her geçen gün artmaktadır. Bu yaklaşımlarda da; litotriptör olarak lazer kullanımı giderek yaygınlaşmaktadır (6-10). Lazer litotriptörler arasında en sık kullanılan holmium lazere ait yapılan çalışmalarda kısa ameliyat süresi, yüksek taşsızlık oranları ve düşük komplikasyon oranları bildirilmiştir $(6,9,11,12)$.

Taşın bulunduğu lokalizasyona bakılmaksızın literatürde holmium lazer kullanılarak yapılan birçok çalışma mevcuttur. Wollin ve ark.'ları 1999 yılında 19 hasta ile yaptıkları çalışmada 6 böbrek taşı ve 13 üreter taşı hastasının 4'üne perkütan nefrolitotomi yöntemiyle 15'ine ise üreteroskopik olarak, holmium lazer litotripsi yapmışlardır. Bu çalışmada ilk operasyondaki taşsızlık oranı \%84 olarak bildirilmiştir. Hastaların tamamında ikinci ameliyat sonrasında taşsızlık sağlanmıştır (13). Atar ve ark.'ları 2013 yılında retrospektif olarak yayınladıkları çalışmada 64 hastanın 35'ine holmium lazer litotripsi ve 29'una pnömotik lazer litotripsi uygulamışlar ve lazer grubunda taşsızlık oranını \%97 olarak saptamışlardır. Öte yandan bu oran pnömotik grubunda ise \%79 olarak saptanmıştır. Aynı çalışmada dikkat çeken bir başka detay ise; lazer grubunda sadece 1 hastada taş migrasyonu gözlenmişken, pnömotik grubunda ise 6 hastada gözlenmesidir (9). Holmium lazer kullanılarak üreter taşlarına yönelik yapılan 412 hasta serilik bir başka çalışmada taşsızlık oranı üst üreterde $\% 74.2$, orta üreterde $\% 87.4$ ve alt üreterde ise \%89.4 olarak belirtilmiştir (14). Benzer bir çalışmada 543 hastada distal üreter taşlarında taşsızlık oranı \%96.8 ve proksimal üreter taşlarında ise bu oran \%79.4 olarak belirtilmiştir (15).

Çocuklarda transüretral holmium lazer litotripsi yapılan ve $<4 \mathrm{~cm}$ mesane taşı olan 33 çocuk hastanın dahil edildiği bir çalışmada çocukların tamamında ortalama 31 dakika sürede taşsızlık sağlanmış ve hiçbir hastada üreteral darlık veya rekürren taş gözlenmemiştir (16). Çocuklarda mesane taşlarında pnömotik litotripsi ve holmium lazer litotripsinin karşılaştırıldığ bir çalışmada 13 hastaya pnömotik, 12 hastaya ise holmium lazer litotripsi uygulanmıştır. Bu çalışmada iki grup arasında komplikasyon ve hastanede kalış süresi arasında fark bulunmazken $<1.5 \mathrm{~cm}$ mesane taşlarında holmium grubunda operasyon süresi daha kısa bulunmuştur (17).

Sonuç olarak Ho:YAG lazer ile litotripsi uygulaması çocuklarda üriner sistemin her bölgesinde (mesane üreter, böbrek) etkin ve başarılıdır. Özellikle üreter taşlarında taş migrasyonunun daha az olması, dokuya travmanın daha az olması gibi nedenlerle, çocuklarda taş hastalıklarında litotripsi yöntemi olarak lazer kullanımını ön plana çıkarmaktadır. Öte yandan minyatürize edilmiş aletlerde (örn: 4,5 F mini URS) daha ince probların bulunması nedeniyle de lazer kullanımı tercih edilmektedir.

\section{Uretral Darlıklarda Holmium Lazer}

Pediatrik uretral darlıklar çok nadiren ve daha çok erkek çocuklarda görülür. Etyolojide daha önce geçirilmiş infeksiyonlar veya iatrojenik nedenler gözlenmektedir. Uretral darlıklar eğer doğru tedavi edilmezlerse çocukta gelecek 
yaşlarında kalıcı ve kötü etkiler bırakabilir. Tedavide amaç mevcut olan en minimal invaziv yöntem ile en yüksek başarı oranı sağlamaktır. Klasik soğuk bıçakla yapılan internal üretrotomiye göre daha az yeniden daralma ve fibrozis oranları elde etmek amacıyla birçok lazer tipi ile çalışmalar yapılmıştır (18-20) Lazer tipleri arasında Holmium lazer, dokularca enerjisi en az abzorbe edildiği için $(0.5 \mathrm{~mm})$, en az skar formasyonu oluşumuna sebep olur ve bu da rekürrens oluşumunu azaltır $(21,22)$.

Erişkin hastalarda bu konu ile ilgili yapılmış birçok çalışma olmasına rağmen çocuklardaki çalışmalar oldukça kısıtlıdır. 2016 yılında Shoukry ve ark.'larının yaptıkları uzun dönem randomize ve prospektif çalışmada ortalama yaşları 5.9 yıl olan 29 erkek hasta çalışmaya dahil edilmiştir. Darlık mesafeleri $2 \mathrm{~cm}$ 'den kısa olan hastaların 3.ay sonuçlarında 23 hastada (\%79.3) tedavi başarısı elde edilmiş iken bu oran 6.ayda 18 hastaya (\%62.1) gerilemiştir. Çalışmanın sonucunda istatistik olarak anlamsız olsa da $>1 \mathrm{~cm}$ ve anterior yerleşimli darlıkların tedaviye daha az yanıt verdiğini bildirmişlerdir (23). Bu çalışmada 4 hastada intraoperatif komplikasyon meydana geldiği yazarlar tarafından rapor edilirken, literatürdeki diğer çalışmada intraoperatif komplikasyon gözlenmemiştir (24). Bu iki çalışma arasında operasyon tekniğindeki farklılık olarak Shoukry ve ark'ları uretraya sadece 12 hizasından kesi yapmışlarken; Futao ve ark. ise 4,8,12'den kesi yapmışlardır.

\section{Posterior Uretral Valv Tedavisinde Lazer}

Posterior uretral valv (PUV) 5000 ile 8000 erkek doğumda 1 gözlenen ancak saptanamaması durumunda morbidite, mortalite ve ilerleyen böbrek hasarına yol açan bir patolojidir. Etyolojisi net bilinmemekle birlikte multifaktöryel gen kaynaklı bir embriyopati olduğu düşünülmektedir. PUV'un güncel tedavisinde, agresif ablasyon sonrası gelişebilecek uretral darlıktan kaçınmak için valv insizyonu daha çok tercih edilmektedir (25). Insizyon metotları elektrokoter, soğuk kesi ve fulgurasyonu içerir. Diatermi ile transuretral ablasyon, lazer ile ablasyonu, hook fulgurasyonu, venöz valvulotom ile insizyon, vizuel soğuk kesi ablasyonu, suprapubik yaklaşımla antegrad valv rezeksiyonu diğer tedavi modaliteleridir.
Literatürde fulgurasyonda en çok Nd:YAG lazer ile ilgili çalışmalar mevcut olsa da; Ho:YAG lazer güncel pratikte belirli avantajları dolayısıyla daha çok kullanılır. Holmium lazer (Ho:YAG) ile kisitl doku penetrasyonu $(0.5 \mathrm{~mm})$ ve termal hasar $(0.5-1 \mathrm{~mm})$ daha az çevre doku inflamasyonu ve ödem dolayısıyla da daha az irritatif işeme semptomuna yol açar $(4,26,27)$. Ho:YAG lazer uygulaması sonrası oluşan kabarcıklar daha küçük ve daha kısa ömürlü olduklarından operasyondaki görüntü Nd:YAG lazere göre daha iyidir (28). Ho:YAG lazerin ince fiberi pediatrik sistoskoptan rahatlikla geçebildiğinden daha geniş çaplı bir rezektoskop kullanımina gerek kalmaz. Bozulmuş koagülasyon profiline sahip PUV hastalarında da Ho:YAG lazer kanama komplikasyonundan kaçınmak amacıyla rahatlıkla kullanılabilir (26).

Mandal ve ark.'ları 2013 yılında yayınladıkları bir çalışmada 40 erkek çocuğa 20-25 w holmium lazer ile primer PUV ablasyonu uygulamışlar ve bu sonuçları retrospektif cohort ile (elektro-fulgurasyon uyguladıkları 40 hasta) ile karşılaştırmışlardır. Çalışmanın sonucunda Ho:YAG grubundaki hastalarda kateter çekilmesi sonrası işeme istatiksel olarak daha başarılı (40'e karşı 32), kateterizasyon zamanı daha kısa (1'e karşı 1.8 gün), operasyon süresi daha kısa (15 vs 20 dakika), uretral darlık gelişimi daha az (0 vs 2) ve üriner inkontinans gelişimi daha az (0 vs 1 ) olarak rapor edilmiştir (29).

\section{Üreteral Fibroepitelyal Polip Tedavisinde Lazer}

Fibroepitelyal polipler üriner traktın herhangi bir yerinden çıkabilen konjenital olduğu düşünülen benign mezenkimal tümörlerdir. Literatürdeki üreteropelvik bileşke obstrüksiyonu serilerine bakıldığında insidansı \%5.2 olarak belirtilmiştir (30). Oluşumlarında kronik irritasyon, infeksiyonlar, obstrüksiyon, travma ve hormonal nedenlerle ilgili çeşitli hipotezler mevcuttur. Çocuklarda sıklıkla üreteropelvik bileşke darlıklarına yönelik yapılan incelemelerde (retrograd pyelogram vs.) ve peroperatif taş cerrahisi (üreteroskopi esnasında) tanı alırlar. En sık semptom hematüri ve flank ağrısıdır. Her ne kadar klinik deneyim sınırlı olsa da; tek ve pediküllü üreteral fibroepitelyal poliplerde Ho:YAG lazer kullanımı oldukça efektiftir (30). Lam ve ark.'ları yayınladıkları çalışmada 5 hastaya perkütan veya endoskopik yak-

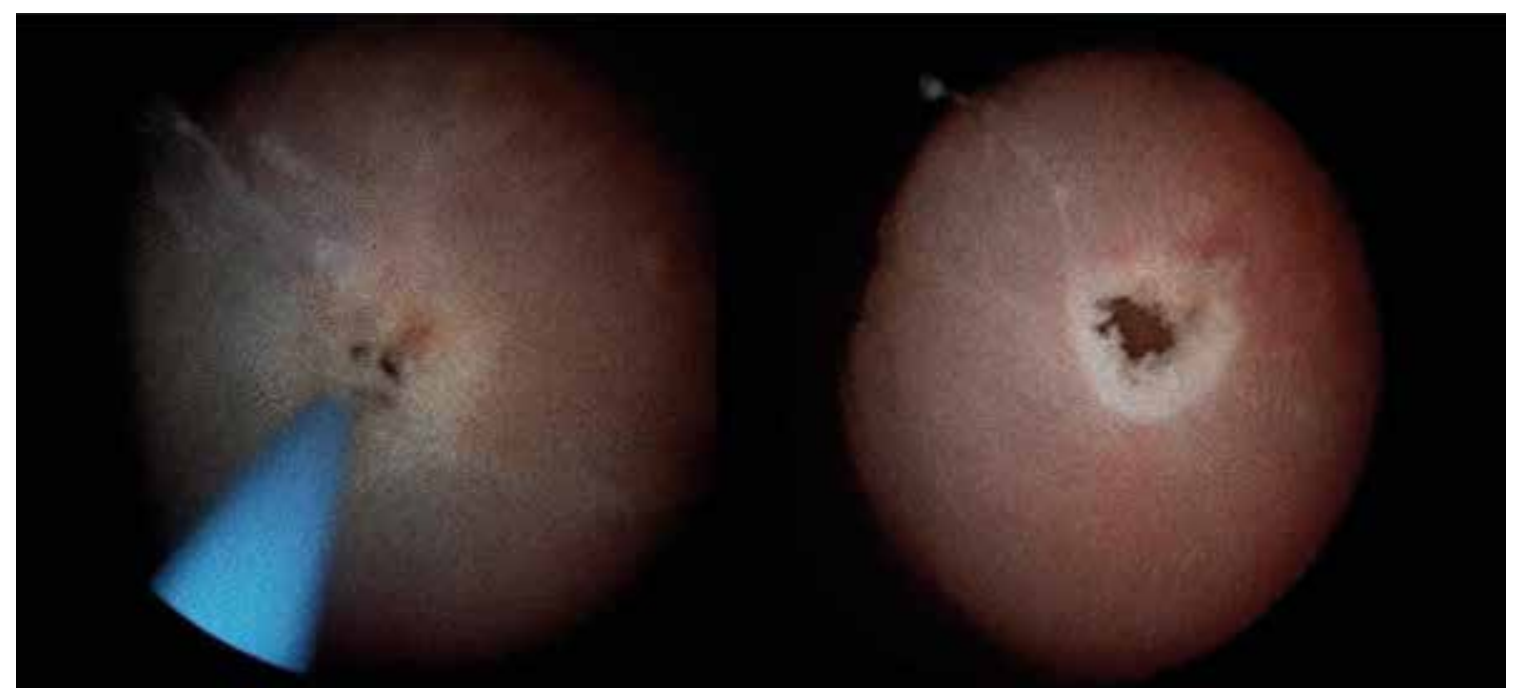

Resim 1 


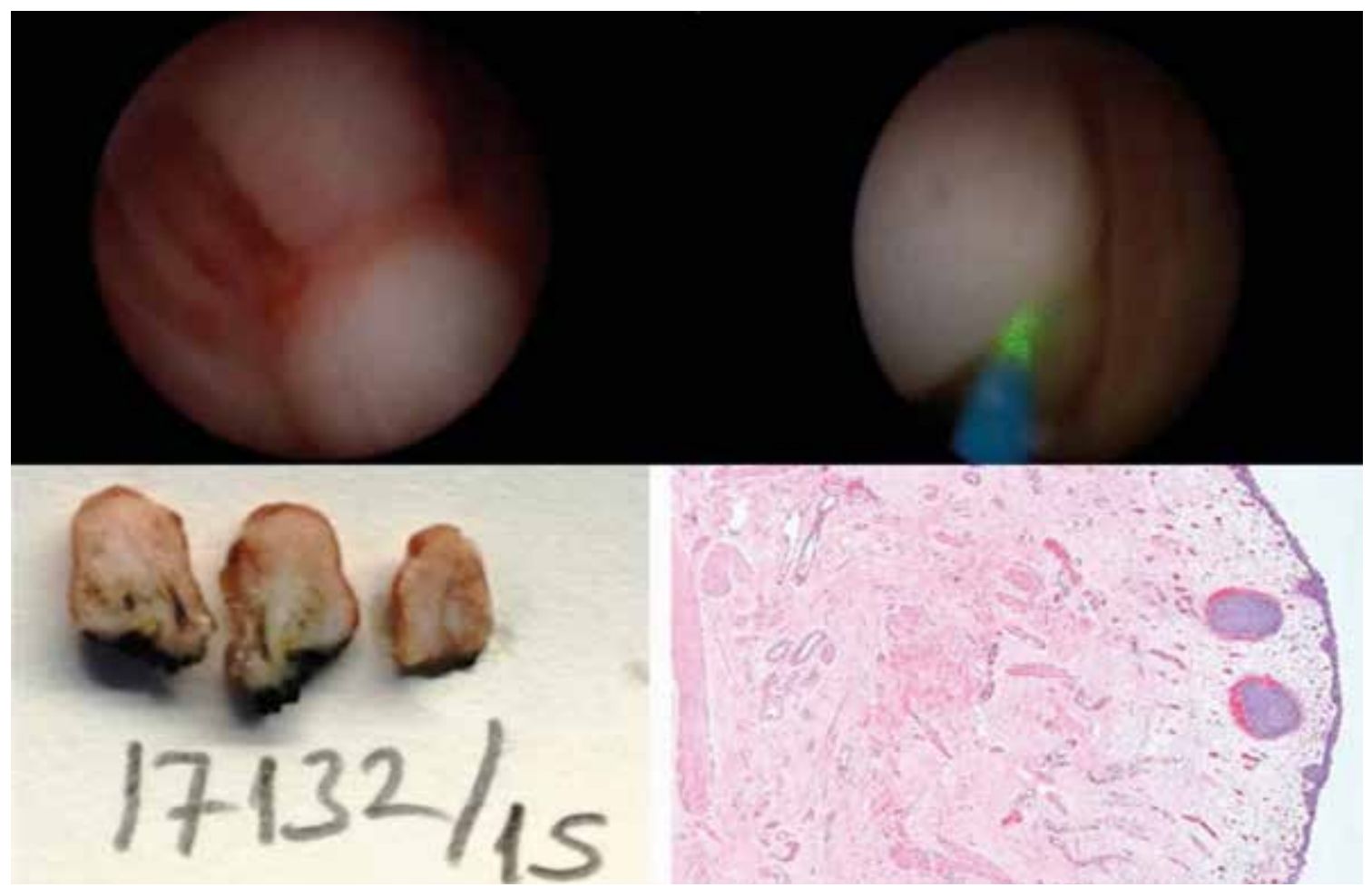

Resim 2

laşımla Ho:YAG lazer ile üreteral polip eksizyonu yapmışlar ve hastaların hiçbirinde rekürrens gözlememişlerdir (31).

\section{Pediatrik Üreterosel Tedavisinde Lazer}

Prenatal ultrasonografi ile hidronefroz tanısının artış göstermesiyle birlikte tanı konulan üreterosel vakalarında ciddi bir artış mevcuttur. Üreteroselin erken dönemde dekompresyonu esnasında lazer kullanımı ile insizyon giderek yaygınlaşmaktadır. Jankowski ve ark.'ları 4 neonatal çocuk hastanın 5 üreteroseline Ho:YAG lazer ile üreterosel dekompresyonu yapmışlar ve üreterosellerin \%80'inde (4/5) ilk girişimde gerekli dekompresyonu sağlamışlardır. Bu çalışmada hiçbir hastada perioperatif veya postoperatif komplikasyon (vezikoüreteral reflü vs.) gözlenmemiştir (32). Resim 1'de kliniğimizde 11 yaşında bir kız çocuğunda Ho:YAG lazer ile ponksiyon uygulanan bir çekoüreterosel olgusu görülmekte$\operatorname{dir}(\operatorname{Resim} 1)$.

\section{Pediatrik Üroloji’de Lazerin Diğer Kullanım Alanları}

Pediatrik üroloji'de yukarıda kısaca bahsedilen kullanımlarının dışında lazerin daha nadir kullanım alanları da mevcuttur. Hemorajik sistit tedavisi (33), hipospadias cerrahisi sonrası gelişen üretral kıl foliküllerinin tedavisi (34), hemanjiom tedavisi (35), otoogmentasyon cerrahisinde detrusurotomi (36), üretral polip eksizyonu (37) nadir kullanımlara örnek gösterilebilir. Resim 2' de kliniğimizde posterior üretral polip eksizyonu yapılan 3 yaşında bir erkek çocuğu olgusu izlenmektedir.

Sonuç olarak; pediatrik olgularda lazer kullanımı taş hastalıkları başta olmak üzere giderek yaygınlaşmaktadır. Endoskopik aletlerin giderek yaygınlaşması ve minyatüri- zasyonu ile birlikte önümüzdeki dönemde lazer kullanımı ile ilgili olarak literatürde birçok klinik çalışmanın yayınlanması beklenmektedir.

\section{Kaynaklar}

1. Wu, H.-Y. and S.G. Docimo, Surgical management of children with urolithiasis. Urologic Clinics of North America, 2004. 31(3): p. 589-594.

2. Harmon, W.J., et al., Ureteroscopy: current practice and long-term complications. The Journal of urology, 1997. 157(1): p. 28-32.

3. ERHARD, M.J. and D.H. BAGLEY, Urologic applications of the holmium laser: preliminary experience. Journal of endourology, 1995. 9(5): p. 383-386.

4. Johnson, D.E., D.M. Cromeens, and R.E. Price, Use of the holmium: YAG laser in urology. Lasers in surgery and medicine, 1992. 12(4): p. 353-363.

5. HULBERT, J.C., et al., Percutaneous nephrostolithotomy: an alternative approach to the management of pediatric calculus disease. Pediatrics, 1985. 76(4): p. 610-612.

6. Sofer, M., et al., Holmium laser ureteroscopic treatment of various pathologic features in pediatrics. Urology, 2007. 69(3): p. 566-569.

7. El-Assmy, A., et al., Safety and outcome of rigid ureteroscopy for management of ureteral calculi in children. Journal of endourology, 2006. 20(4): p. 252-255.

8. Unsal, A. and B. Resorlu, Retrograde intrarenal surgery in infants and preschool-age children. Journal of pediatric surgery, 2011. 46(11): p. 2195-2199.

9. Atar, M., et al., Comparison of pneumatic and laser lithotripsy in the treatment of pediatric ureteral stones. Journal of pediatric urology, 2013. 9(3): p. 308-312. 
10. Dogan, H.S., et al., Use of the holmium: YAG laser for ureterolithotripsy in children. BJU international, 2004. 94(1): p. 131-133.

11. Schuster, T.G., et al., Ureteroscopy for the treatment of urolithiasis in children. The Journal of urology, 2002. 167(4): p. 1813-1816.

12. Al-Busaidy, S., et al., Ureteric calculi in children: preliminary experience with holmium: YAG laser lithotripsy. BJU international, 2004. 93(9): p. 1318-1323.

13. WOLLIN, T.A., et al., Holmium: YAG lithotripsy in children. The Journal of urology, 1999. 162(5): p. 1717-1720.

14. Imamura, Y., et al., Development of a nomogram for predicting the stone-free rate after transurethral ureterolithotripsy using semi-rigid ureteroscope. Int J Urol, 2013. 20(6): p. 616-21.

15. Seitz, C., et al., Impact of stone size, location, composition, impaction, and hydronephrosis on the efficacy of holmium: YAG-laser ureterolithotripsy. european urology, 2007. 52(6): p. 1751-1759.

16. Aboulela, W., et al., Transurethral Holmium Laser Cystolithotripsy in Children: Single Center Experience. Journal of Endourology, 2015. 29(6): p. 661-665.

17. Gangkak, G., et al., Pneumatic cystolithotripsy versus holmium: yag laser cystolithotripsy in the treatment of pediatric bladder stones: a prospective randomized study. Pediatric surgery international, 2016: p. 1-6.

18. Rothauge, C., Urethroscopic recanalization of urethral stenosis using argon laser. Urology, 1980. 16(2): p. 158161.

19. Smith Jr, J. and J. Dixon, Neodymium: YAG laser treatment of benign urethral strictures. The Journal of urology, 1984. 131(6): p. 1080-1081.

20. Turek, P.J., et al., KTP-532 laser ablation of urethral strictures. Urology, 1992. 40(4): p. 330-334.

21. Matsuoka, K., et al., Endoscopic antegrade laser incision in the treatment of urethral stricture. Urology, 2002. 60(6): p. 968-972.

22. Kamp, S., et al., Low-power holmium: YAG laser urethrotomy for treatment of urethral strictures: functional outcome and quality of life. Journal of endourology, 2006. 20(1): p. 38-41.

23. Shoukry, A.I., et al., Use of holmium laser for urethral strictures in pediatrics: A prospective study. J Pediatr Urol, 2016. 12(1): p. 42 e1-6.

24. Futao, S., et al., Application of endoscopic Ho: YAG laser incision technique treating urethral strictures and urethral atresias in pediatric patients. Pediatric surgery international, 2006. 22(6): p. 514-518.
25. Lal, R., V. Bhatnagar, and D. Mitra, Urethral strictures after fulguration of posterior urethral valves. Journal of pediatric surgery, 1998. 33(3): p. 518-519.

26. Marks, A.J. and J.M. Teichman, Lasers in clinical urology: state of the art and new horizons. World journal of urology, 2007. 25(3): p. 227-233.

27. Phillips, C.K. and J. Landman, Lasers in the upper urinary tract for non-stone disease. World journal of urology, 2007. 25(3): p. 249-256.

28. Larizgoitia, I. and J. Pons, A systematic review of the clinical ef? cacy and efectiveness of the holmium: YAG laser in urology. BJU international, 1999. 84: p. 1-9.

29. Mandal, S., et al., Use of holmium: YAG laser in posterior urethral valves: another method of fulguration. Journal of pediatric urology, 2013. 9(6): p. 1093-1097.

30. Li, R., et al., Diagnosis and management of ureteral fibroepithelial polyps in children: A new treatment algorithm. Journal of pediatric urology, 2015. 11(1): p. 22. e1-22. e6.

31. Lam, J.S., J.B. Bingham, and M. Gupta, Endoscopic treatment of fibroepithelial polyps of the renal pelvis and ureter. Urology, 2003. 62(5): p. 810-813.

32. Jankowski, J.T. and J.S. Palmer, Holmium: yttrium-aluminum-garnet laser puncture of ureteroceles in neonatal period. Urology, 2006. 68(1): p. 179-81.

33. Gweon, P. and A. Shanberg, Treatment of cyclophosphamide induced hemorrhagic cystitis with neodymium: YAG laser in pediatric patients. The Journal of urology, 1997. 157(6): p. 2301-2302.

34. Kirsch, A.J., et al., Skin flap closure by dermal laser soldering: a wound healing model for sutureless hypospadias repair. Urology, 1997. 50(2): p. 263-272.

35. Kim, Y.Y., et al., Multiple hemangiomas of the urinary bladder in a child with gross hematuria. Ultrasonography, 2015. 34(3): p. 231.

36. Poppas, D.P., et al., Laparoscopic laser assisted autoaugmentation of the pediatric neurogenic bladder: early experience with urodynamic followup. The Journal of urology, 1996. 155(3): p. 1057-1060.

37. Akbarzadeh, A., R. Khorramirouz, and A.-M. Kajbafzadeh, Congenital urethral polyps in children: Report of 18 patients and review of literature. Journal of pediatric surgery, 2014. 49(5): p. 835-839.

Yazışma Adresi:

Mesrur Selçuk Silay,

Medeniyet Üniversitesi Göztepe Ĕ̆itim ve Araştırma Hastanesi, Çocuk Ürolojisi Bilim Dalı, İstanbul

Tel: +90 5056454005

e-mail: selcuksilay@gmail.com 